\title{
INFLUENCE OF FIBER ORIENTATION ON THE
}

\section{PROPERTIES OF COMPOSITES}

\section{ASHOK KUMAR ${ }^{1}$, K. DEEPAK ${ }^{2}$,}

\section{CH. V. K. N. S. N. MOORTHY ${ }^{3} \&$ B. SUBRAMANYAM ${ }^{4}$}

${ }^{1,2}$ Department of Mechanical Engineering, Vardhaman College of Engineering, Hyderabad, India

${ }^{3}$ Department of Mechanical Engineering, Institute of Aeronautical Engineering, Hyderabad, India

${ }^{4}$ Department of Mechanical Engineering, MLR Institute of Technology, Hyderabad, India

ABSTRACT
Damage pattern on the surface of laminate with fiber orientations $\left(0^{0} / 15^{\circ}\right),\left(0^{\circ} / 30^{\circ}\right)$, and $\left(0^{0} / 45^{\circ}\right)$ have been
studied. E-glass/Epoxy composite laminate of thickness $4 \mathrm{~mm}$ with size $100 \mathrm{mmx} 100 \mathrm{~mm}$ clamped on all the edges has been
used. The laminate is subjected to quasi-static indentation at center with $8 \mathrm{~mm}$ diameter steel ball indenter. Damage is
quantified in terms of opacity of the indented area, that represent delaminations, debonds and fiber fracture. Results
indicated that damage is directly proportional to the fiber angle and also the internal damage is limited to the surrounding
area of indentation spot. Observations from scanning electron micrographs have been correlated with visual observations.
KEYWORDS:Delamination, Epoxy, Fiber,Indentation \& Laminate

Received: Nov 22, 2017; Accepted: Dec 18, 2017; Published: Jan 08, 2018; Paper Id.: IJMPERDFEB201854

\section{INTRODUCTION}

Fiber-reinforced composites are widely used in shipbuilding, aerospace and other commercial applications whenever high specific modulus, low specific weight, and damage tolerance are needed. The composites play significant role of absorbing energy due to intralaminar and interlaminar damage mechanisms like matrix crack, delamination, and fiber breakage. Therefore, estimation of penetration resistance, damage and energy absorption has become difficult. Sun et al. [1] presented that the damage mechanism in low velocity impact is same as that of quasi-static loading. The indenter displacements for damage in static and dynamic loading were comparable. Due to difference in strain rate the degree of damage per unit time was different. Johnson et al. [2] developed a computation method based on CDM model to predict impact damage of composite structures. Yen et al. [3] presented a damage model by generalizing the layer failure model in LS-DYNA. The load-displacement curve presented by Sun et al. [4] shows a small drop in load indicating the initiation of delamination in the laminate. The increase in load exhibits an oscillatory nature during the progress of delamination. After reaching the peak load, it drops suddenly to a minimum value and stays at that level. This corresponds to the friction that develops between punch and laminated plate. The damage mechanism approach incorporate softening behavior and progressive damage of a laminate after damage initiation. Matzenmiller et al. [5]. Williams et al. [6] used principles of damage mechanism along with the fiber and matrix failure criteria to analyse damage in low velocity loading. Loaddisplacement curves and damage patterns were comparable with the experimental results. 


\section{METHODOLOGY}

Composite laminates have been prepared by passing the 1200 TEX E-glass fibers through the resin bath containing epoxy mixed with hardener at a constant temperature of $45^{\circ} \mathrm{C}$. These fibers are then wound on a cylindrical drum rotating at $15 \mathrm{rpm}$. After winding on the drum completely, it is opened and layed on a flat platform in the open atmosphere for 48 hours for tackiness. It is then cut into convenient sizes and placed one above the other till the desired thickness of the laminate is achieved. These overlapped layers are compressed between the two parallel flat steel plates with spacers of required laminate thickness. The plates have been clamped using nut and bolt. Thelaminate in the clamped state is placed in an oven. The temperature is maintained at $80^{\circ} \mathrm{C}$ for first four hours and then $120^{\circ} \mathrm{C}$ for another four hours. The entrapped gases are removed in the initial four hours and then more four hours were provided for the chemical reaction to occur between the epoxy and the hardener for permanent set and finally resulted in a single solid laminate. After curing the laminate for 8 hours, the oven is switched off to reduce the temperature in the oven to normal temperature. The edges are trimed and the laminates are thus preparedfor testing.
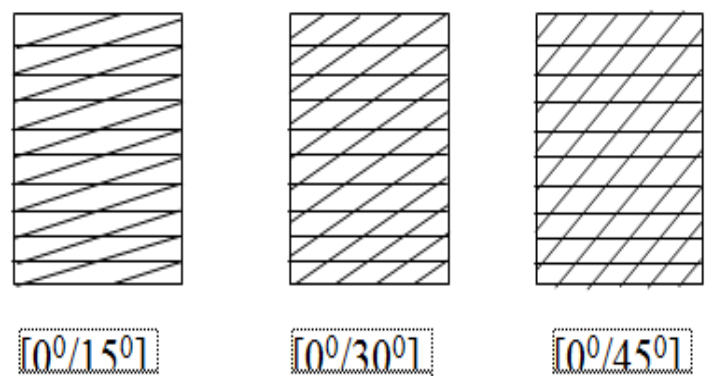

\section{Figure 1: Fiber Orientation in Laminae}

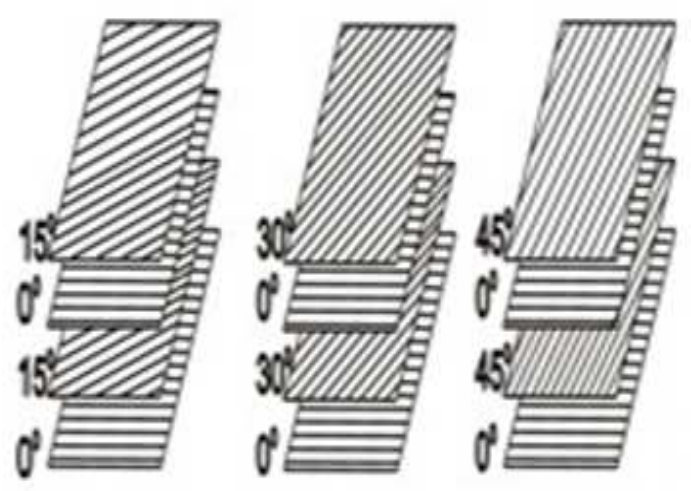

Figure 2: Layup Sequence of Laminae 


\section{EXPERIMENTAL PROCEDURE}

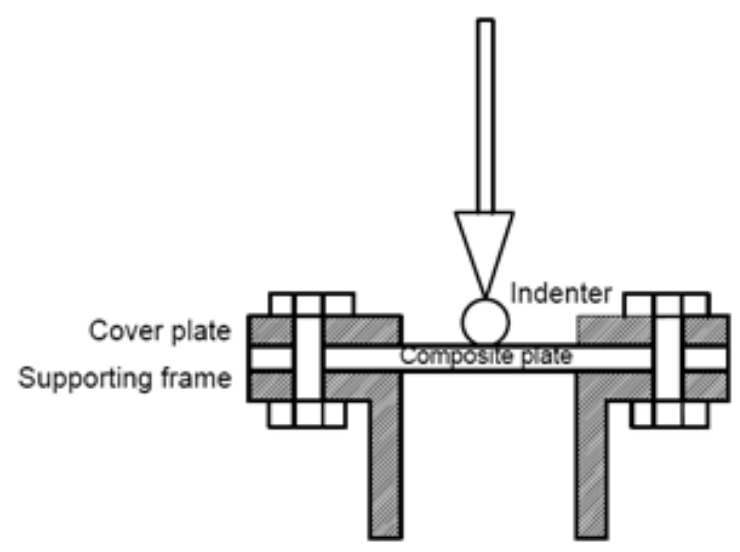

Figure 3. Schematic of Indentation

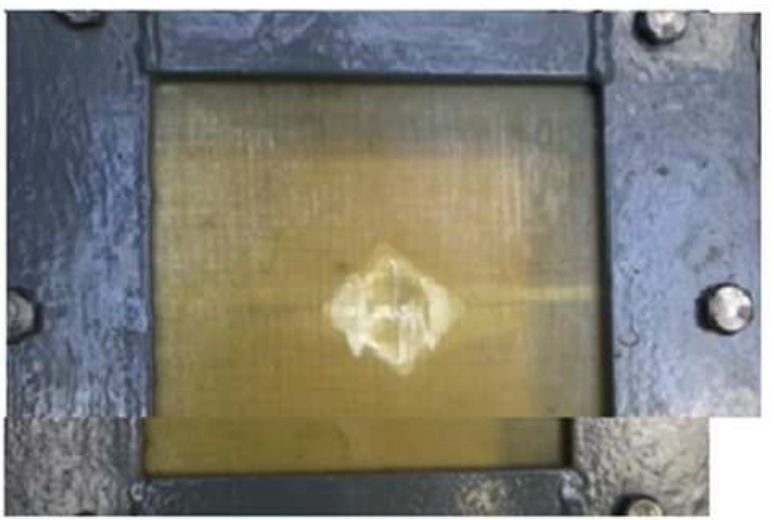

Figure 4: Laminate Clamped and Indented

Indentation tests have been conducted quasi-statically on a universal testing machine (UTM)for different composite laminated plates with fiber orientations of $\left[0^{0} / 15^{0}\right]_{20}$, $\left[0^{0} / 30^{0}\right]_{20}$, and $\left[0^{0} / 45^{0}\right]_{20}$. The laminates are placed on a steel frame and are covered with a plate having square opening of size $60 \mathrm{~mm} \times 60 \mathrm{~mm}$. It is than clamped rigidly using nut and bolt as shown in the Figure. 3. The assembly is then placed on the platform of the UTM. A steel ball indentor of diameter $8 \mathrm{~mm}$ is used for indentation. The tests are carried out for the indenterdisplacement of $0.1 \mathrm{~mm} / \mathrm{minute}$ up to a displacement of $5 \mathrm{~mm}$. The Load on the composite laminateis quantified by the load cell ofUTM. Figure. 4 depicts theclamped laminate with indentation.

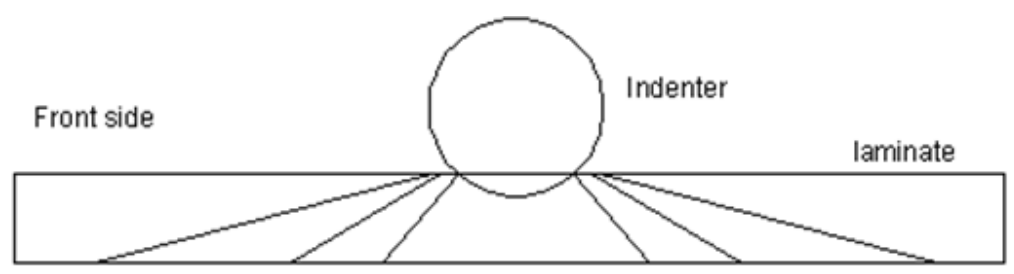

Back side

Figure 5: Propagation of Stress Wave from Top to Bottom Face 


\section{Stress Distribution}

When load is applied on the surface of laminate by an indenter, the stress wave developed by the load will start propagating from the top surface of laminate to bottom surface in radial outward direction flowing from the center of indenter as shown in Figure. 5 and decides the damage area on the surface of the laminate. The magnitude of stress depends on the structure of laminate and the magnitude of indenter displacement. The laminates after indentation and the geometric damage pattern are depicted in Figure. 6 and Figure. 7.
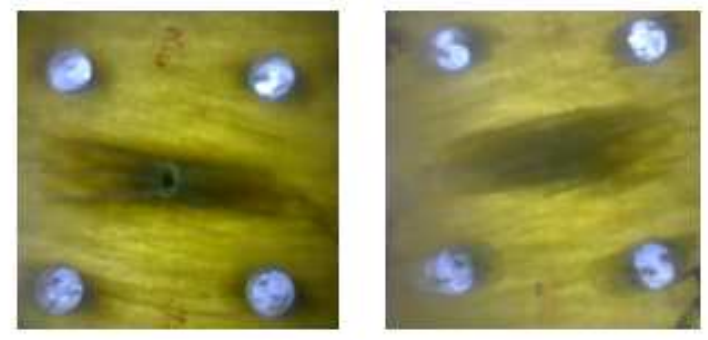

$\left[0 / 30^{0}\right]$
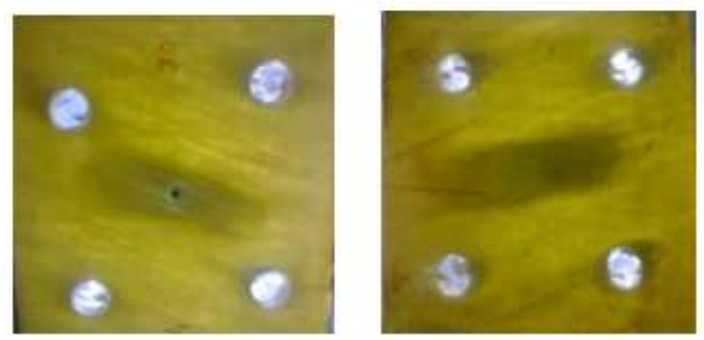

$\left[0 / 45^{0}\right]$
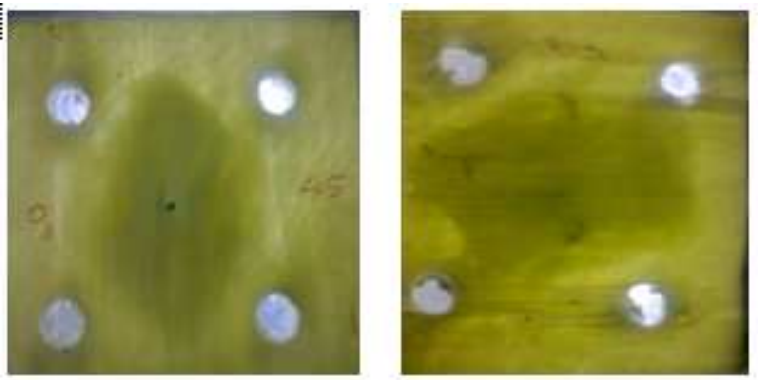

$\left[0 / 45^{\circ}\right]$

Figure 6: Laminates After Indentation

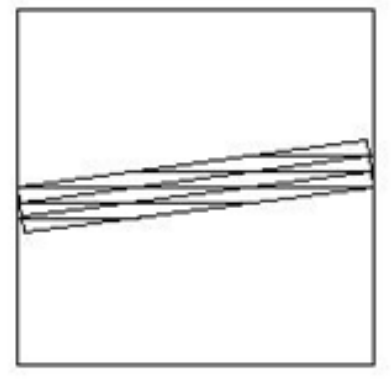

$(0 / 15)$

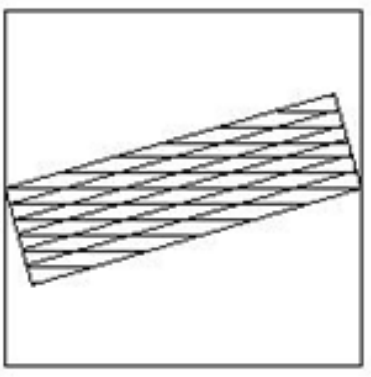

$(0 / 30)$

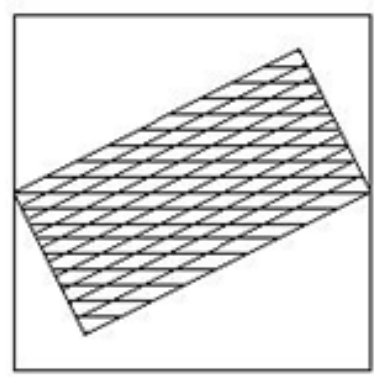

$(0 / 45)$

Figure 7: Geometric Damage Pattern

\section{Load-Displacement}

The load has increased proportionally with the indenter displacement for all the laminates up to a displacement of $0.5 \mathrm{~mm}$ and there after, it remains almost same for both $\left[0^{0} / 15^{0}\right]$ and $\left[0^{0} / 30^{0}\right]$ laminate. For $\left[0^{0} / 45^{0}\right]$ laminate, load curve is following a parabolic instead of linear path because of matrix crack, fiber break and delamination occurring after $0.5 \mathrm{~mm}$ of displacement. It is also observed that for $\left[0^{0} / 45^{0}\right]$ the load is lower at all the indenter displacements compared to $\left[0^{0} / 15^{0}\right]$ 
and $\left[0^{0} / 30^{0}\right]$ laminates. The load at the end of indenter displacement is slightly higher for $\left[0^{0} / 30^{\circ}\right]$ laminate than for $\left[0^{0} / 15^{0}\right]$ laminate as shown in Figure.8.

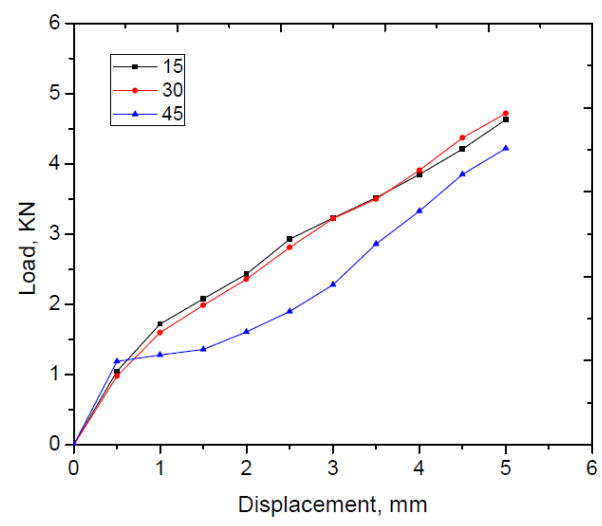

Figure 8: Load as a Function of Indenter Displacement

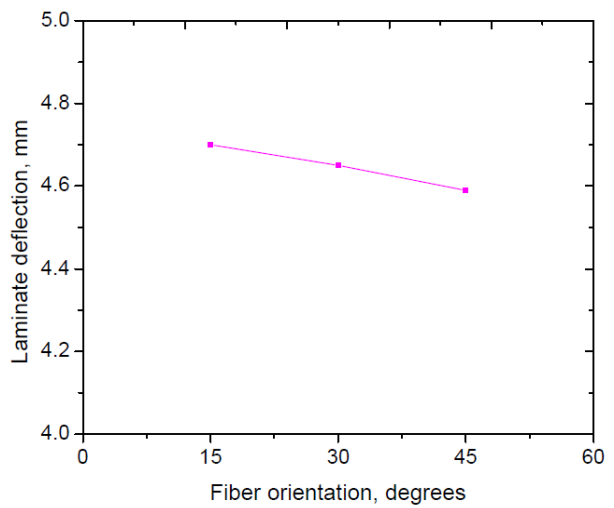

Figure 9: Deflection of Laminates vs. Fiber Orientation

\section{Laminate Deflection}

The deflection of the laminate below indentation point at the bottom side of it is decreasing with the increase in fiber orientation. The laminate with fiber orientation $\left[0^{0} / 15^{0}\right]$ has maximum and $\left[0^{0} / 45^{0}\right]$ has minimum deflection as shown in Figure. 9.

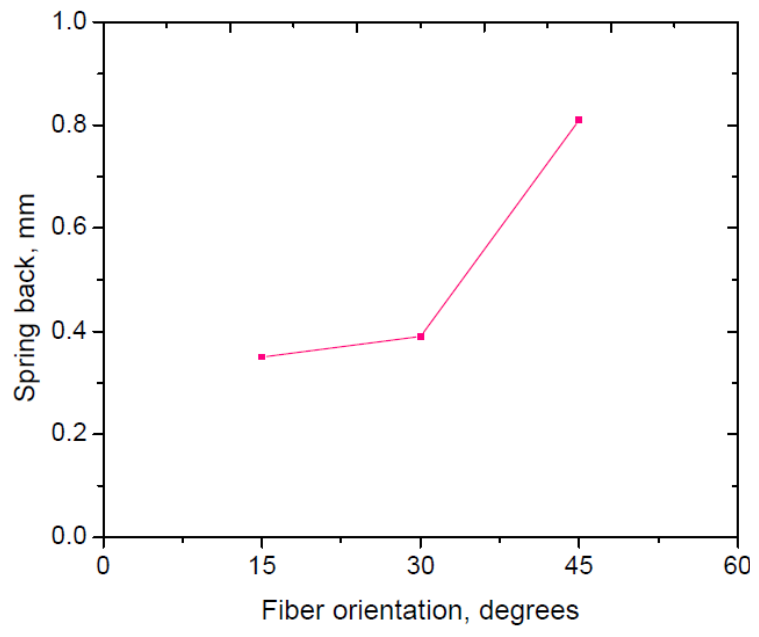

Figure 10: Spring Back vs. Fiber Orientation 


\section{Spring Back}

Spring back is a small recovery of indentation depth after removal of indenter from the laminate. It is observed that there is a gradual increase in the spring back for the laminates with fiber orientation from $\left[0^{0} / 15^{0}\right]$ to $\left[0^{\circ} / 30^{0}\right]$ and then onwards it raised rapidly up to $\left[0^{0} / 45^{0}\right]$ laminate as shown in Figure. 10.

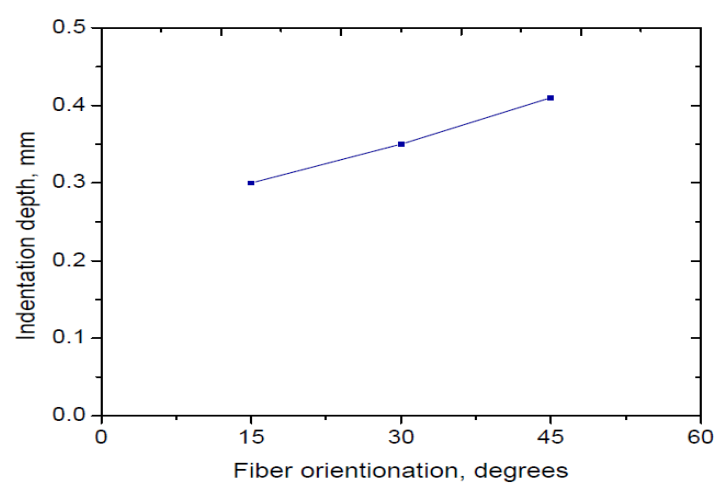

\section{Figure11: Indentation of Laminates Vs. Fiber Orientation}

\section{Indentation Depth}

When load on the laminate exceed beyond elastic limit then plastic nature in the laminate begins, that may cause a dent in the laminate surface. Depth of indentation is increasing with the increase in fiber orientation. Thisclearly indicatesthe increasing plastic nature of laminate with the increase in fiber orientation as shown in Figure.11.

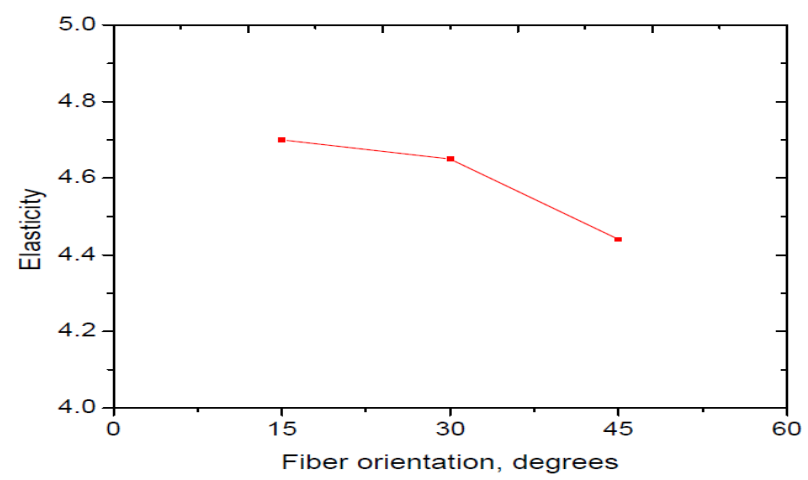

Figure 12: Elasticity of Laminates Vs. Fiber Orientation

\section{Elasticity}

The elastic nature of the laminate with fiber orientation $\left[0^{0} / 15^{0}\right]$ is very large compared to the laminate with fiber orientation $\left[0^{0} / 45^{0}\right]$. There is a gradual decrease in elasticity from $\left[0^{0} / 15^{0}\right]$ to $\left[0^{0} / 30^{0}\right]$ and sudden fall up to $\left[0^{0} / 45^{0}\right]$ laminate as shown in Figure.12. 


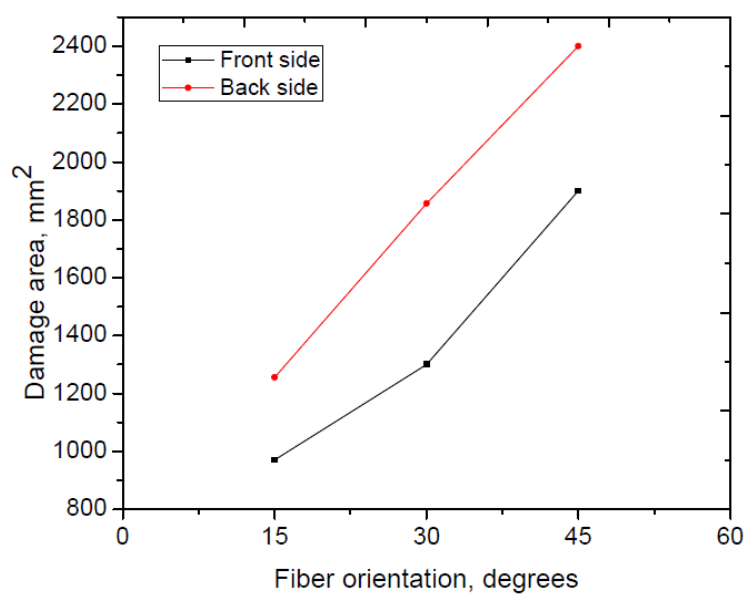

Figure 13: Damage Area of Laminates Vs. of Fiber

\section{Damage Area}

Damage area that is defined as matrix crack, delamination and fiber break, observed to be minimum for the laminate with fiber orientation $\left[0^{0} / 15^{0}\right]$ and maximum for $\left[0^{0} / 45^{0}\right]$. For all fiber orientation, the damage area appears to be more on the back side of the laminate compared to the front side as depicted in the Figure. 13.

\section{Scanning Electron Micrograph}

SEM photographs shows clearly that there is a small fiber breakage in $\left[0^{0} / 15^{0}\right]$ laminate, where as in the case of $\left[0^{0} / 30^{0}\right]$ and $\left[0^{0} / 45^{0}\right]$ laminate apart from breakage, crushing of the fibers have also taken place. However more damage has occurred in $\left[0^{0} / 30^{\circ}\right]$ than $\left[0^{\circ} / 45^{\circ}\right]$ laminate as shown in Figure. 14.

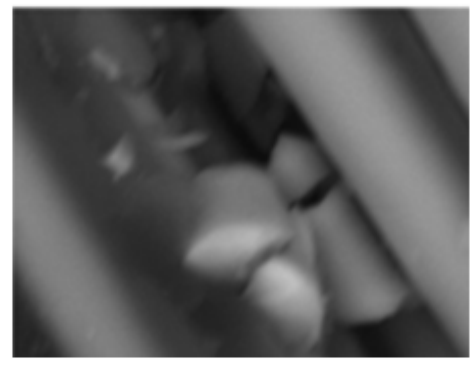

$\left[0^{0} / 15^{0}\right]$ laminate

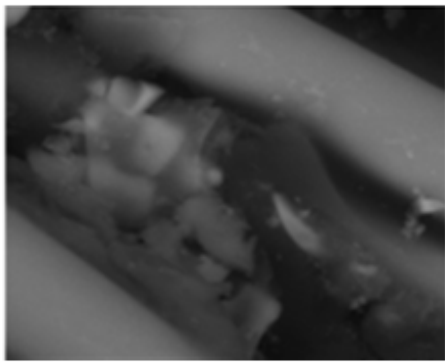

$\left[0^{0} / 15^{0}\right]$ laminate

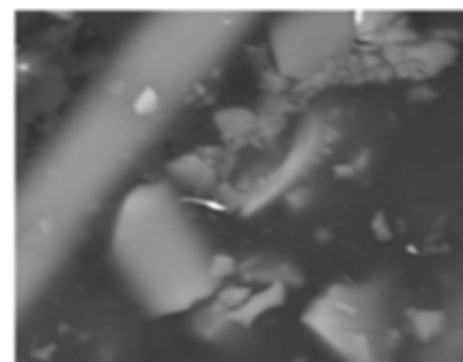

$\left[0^{0} / 45^{0}\right]$ laminate

Figure 14: Microstructure of Indented Areas

\section{CONCLUSIONS}

- Among all indenter displacements, load is minimum for $\left[0^{0} / 45^{0}\right]$ laminate.

- Laminates with increased fiber orientation increases the Spring back.

- Indentation depth is increaseslinearly with the fiber orientation.

- The increase in fiber orientation decreases the deflection of laminate.

- The elasticity of laminate decreases with increased fiber orientation.

- Damage area increases with the increased fiber orientation. 
- $\quad$ Damage area will be more on the bottom side of laminate for any fiber orientation.

\section{REFERENCES}

1. Sun C.T., Potti S.V. (1996). A simple model to predict residual velocities of thick composite laminates subjected to high velocity impact. International Journal of Impact Engineering, 18(3), 339-53.

2. Sudhanshu Krishna Sharma et.al.,, A Review on Acoustical Properties Measurement Methods and a Proposed Novel Method for Acoustical Characterization of Laminated Glass used in Automotive Applications, International Journal of Mechanical and Production Engineering Research and Development (IJMPERD), Volume 7, Issue 4, July - August 2017, pp. 275-290

3. Johnson A.F., Picket A.K., Rozycki P. (2001). Computational methods for predicting impact damage in composite structures. Composite Science Technology,61(15), 2183-2192.

4. Yen C.F., Caiazzo A. (2001).Innovative processing of multifunctional composite armor for ground vehicles. ARL Technical Report ARLCR-484, U.S Army Research Laboratory, Aberdeen Proving Ground, MD.

5. Muhsin J. Jweeg \& Muhannad Al-Waily, Analytical Investigation of Time Dependent Tensional Loading of Stiffened and UnStiffened Composite Laminated Plates, International Journal of Mechanical and Production Engineering Research and Development (IJMPERD), Volume 3, Issue 3, September - October 2013, pp. 77-90

6. Sun C.T., Potti S.V. (1997). Prediction impact induced penetration and delamination in thick composite laminates. International Journal of Impact Engineering, 19(1), 31-48.

7. Matzenmiller A.,Lublinear J., Taylor R.L. (1995). A constitutive model for anistropic damage in fiber composites, Mechanics of Materials, 20(2), 125-152.

8. Williams K.V.,Vaziri R. (2001).Application of a damage mechanics model for predicting the impact response of composite materials.Computers and Structues, 79(10), 997-1011. 